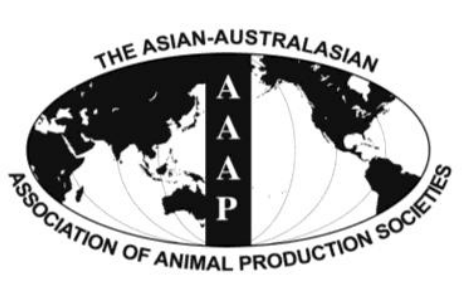

Open Access

Asian Australas. J. Anim. Sci.

Vol. 28, No. $3:$ 435-441 March 2015

http://dx.doi.org/10.5713/ajas.14.0322

www.ajas.info

pISSN 1011-2367 elSSN 1976-5517

\title{
Correlations among Stress Parameters, Meat and Carcass Quality Parameters in Pigs
}

\author{
Marija Dokmanovic, Milan Z. Baltic, Jelena Duric, Jelena Ivanovic*, Ljuba Popovic ${ }^{1}$, \\ Milica Todorovic, Radmila Markovic, and Srdan Pantic \\ Faculty of Veterinary Medicine, University of Belgrade, Belgrade 11000, Serbia
}

\begin{abstract}
Relationships among different stress parameters (lairage time and blood level of lactate and cortisol), meat quality parameters (initial and ultimate $\mathrm{pH}$ value, temperature, drip loss, sensory and instrumental colour, marbling) and carcass quality parameters (degree of rigor mortis and skin damages, hot carcass weight, carcass fat thickness, meatiness) were determined in pigs $(\mathrm{n}=$ 100) using Pearson correlations. After longer lairage, blood lactate $(\mathrm{p}<0.05)$ and degree of injuries $(\mathrm{p}<0.001)$ increased, meat became darker $(p<0.001)$, while drip loss decreased $(p<0.05)$. Higher lactate was associated with lower initial $\mathrm{pH}$ value $(\mathrm{p}<0.01)$, higher temperature $(\mathrm{p}<0.001)$ and skin blemishes score $(\mathrm{p}<0.05)$ and more developed rigor mortis $(\mathrm{p}<0.05)$, suggesting that lactate could be a predictor of both meat quality and the level of preslaughter stress. Cortisol affected carcass quality, so higher levels of cortisol were associated with increased hot carcass weight, carcass fat thickness on the back and at the sacrum and marbling, but also with decreased meatiness. The most important meat quality parameters $(\mathrm{pH}$ and temperature after 60 minutes) deteriorated when blood lactate concentration was above 12 mmol/L. (Key Words: Pig, Blood Lactate, Preslaughter Stress, Meat Quality, Carcass Quality)
\end{abstract}

\section{INTRODUCTION}

The production of high quality pork has been a constant objective of the pig industry for many decades. The main goal is to obtain pigs with high lean percentage and good meat quality traits at the same time. However, this goal has proved difficult to achieve (Kusec et al., 2003). Meat and carcass quality are complex traits and are influenced by many antemortem and postmortem factors (Sellier and Monin, 1994; Huff-Lonergan et al., 2002). The prediction and evaluation of pork quality is of particular importance if these traits are to be improved. Many physical and biochemical factors have been evaluated in an attempt to assess meat quality (Huff-Lonergan et al., 2002).

There are three important parameters to define pork quality: drip loss, ultimate pH and colour (Lee et al., 2000).

\footnotetext{
* Corresponding Author: Jelena Ivanovic.

E-mail: 1310jecko@gmail.com

${ }^{1}$ Ministry of Agriculture, Forestry and Water Management, Belgrade 11000, Serbia.

Submitted Apr. 30, 2014; Revised Aug. 20, 2014; Accepted Sept. 5, 2014
}

Using those parameters, meat can be classified into the five quality categories; PSE (pale, soft, exudative), normal or RFN (red, firm, nonexudative), DFD (dark, firm, dry), RSE (reddish-pink, soft, exudative) and PFN (pale, firm, nonexudative) meat (Kauffman et al., 1992). It is well known that changes in some meat quality traits can affect many other meat quality attributes and pork quality overall (HuffLonergan et al., 2002).

In addition, changes in physiological parameters affect meat quality. Increase in blood lactate concentration is associated with pre-slaughter stress, which has been shown to have a detrimental effect on pork quality (Hambrecht et al., 2005a, b; Edwards et al., 2010b). Hambrecht et al. (2004) determined that pigs exposed to aggressive handling just prior to stunning had a higher blood lactate concentration at slaughter and exhibited pork with higher drip loss and thus proposed that lactate was a potential indicator of both physical and psychological stress associated with the handling of pigs immediately before slaughter. Furthermore, the level of cortisol is an individual characteristic of each animal (Mormede, 2007) and it

Copyright (? 2015 by Asian-Australasian Journal of Animal Sciences This is an open-access article distributed under the terms of the Creative Commons Attribution Non-Commercial License (http://creativecommons.org/licenses/by-nc/3.0/) which permits unrestricted non-commercial use, distribution, and reproduction in any medium, provided the original work is properly cited. 
affects the amount of fat in the body, meatiness, and thus, carcass quality (Foury et al., 2005; 2007; Skrlep et al., 2009). Higher cortisol levels were associated with higher initial and ultimate $\mathrm{pH}$ values, and consequently with lower Minolta $\mathrm{L}^{*}$ and $\mathrm{b}^{*}$ values and drip loss after 24 and 48 hours suggesting that cortisol level at slaughter reflects on meat quality (Skrlep et al., 2009).

Considering relationships between biochemical traits and objective measures of quality, and complex biological mechanisms behind their development, the objective of this study was to determine to what extent different animal stress, meat quality and carcass quality traits were associated.

\section{MATERIAL AND METHODS}

\section{Animals, housing and feeding}

The experiment was conducted on 100 commercial market pigs (31 gilts, 51 barrows and 18 boars), six months old and with live weight between 115 and $130 \mathrm{~kg}$. All animals were of the same origin (cross between Naima sows and hybrids P-76 PenArLan boars) and came from the same farm. Pigs were housed in the finishing facility on partially slatted floors, in pens with 20 animals per pen (stocking density $=1 \mathrm{~m}^{2} / \mathrm{pig}$ ). Pigs were provided with $\mathrm{ad}$ libitum feed and water.

\section{Pre-slaughter handling}

Before transport feed and water were not withdrawn. Pigs from the same pen were transported together, without mixing with other pigs, in batches of 20 animals in a transportation trailer (stocking density was $0.45 \mathrm{~m}^{2}$ per pig). The distance between pens and vehicle at loading was about $20 \mathrm{~m}$ and the slope of the loading ramp was $15^{\circ}$. Transport from farm to the abattoir lasted 15 minutes. The surface of the vehicle and the unloading area were on the same level. After unloading, pigs entered a $10 \mathrm{~m}$ long corridor that led to the lairage pens. During loading and unloading sticks and electric prods were used to move pigs.

During lairage, pigs were not mixed and stocking density was $0.70 \mathrm{~m}^{2}$ per pig. Pigs were held in lairage less than 3 hours (slaughtered on the same day when they arrived, $\mathrm{n}=28$ ) or more than 14 hours (stayed overnight and slaughtered in the morning, $n=72$ ). The exact length of lairage time was measured for each pig.

Between lairage pens and stunning area was 5-m single file corridor. During pig handling from lairage pens to the stunning area stick and electric prod were used randomly. After lairage pigs were head-only electrically stunned (50 $\mathrm{Hz}, 2 \mathrm{~A}$ and $220 \mathrm{~V}$ ) in batches of 6 animals without restraining. Immediately after stunning pigs were bled on the floor and then hoisted on a rail. Following bleeding carcasses were processed using conventional industry practice.

\section{Blood sampling and determination of blood lactate and cortisol content}

At slaughter blood samples were taken into plastic tubes and part of material was transferred to vacutainer tubes containing heparin (against blood coagulation). Thereupon blood lactate content was determined using a portable lactate analyzer (Lactate Scout, EKF Diagnostic, Magdeburg, Germany). The lactate analyzer was tested with a standard solution to ensure accuracy. After blood collection the vacutainer tubes were placed on ice and within 4 to 6 hours blood was centrifuged at 3,000 rpm for 3 minutes. Supernatants (plasma) were collected into microtubes and stored at $-20^{\circ} \mathrm{C}$ until the determination of cortisol concentration by radioimmunoassay (RIA-CT Cortisol, INEP, Belgrade, Serbia).

\section{Meat and carcass quality analyses}

Meat quality measurements were carried out 60 minutes, 24 and 72 hours after slaughter on muscle Longissimus dorsi (LD), pars lumbalis. Values of $\mathrm{pH} 60$ minutes and 24 hours postmortem $\left(\mathrm{pH}_{60 \mathrm{~min}}, \mathrm{pH}_{24 \mathrm{~h}}\right)$, and temperature 60 minutes postmortem $\left(\mathrm{t}_{60 \mathrm{~min}}\right)$ were measured using a $\mathrm{pH}$ meter Testo 205 (Germany) calibrated with $\mathrm{pH} 4.00$ and 7.00 phosphate buffer. Skin damages were assessed by three observers on three carcass regions (from head to back of shoulder, from back of shoulder to hind-quarters and region of hind-quarters) immediately after dressing using scores 1 (no damages), 2 (scratches or small wounds, less than $2 \mathrm{~cm}$ ), 3 (bleeding wounds between 2 and $5 \mathrm{~cm}$ or a healed wounds of more than $5 \mathrm{~cm}$ ) and 4 (deep and open wounds of more than $5 \mathrm{~cm}$ ). The final skin damages score for each carcass was obtained by summing scores for the three regions, and ranged from 3 to 12. Degree of rigor mortis was estimated on right carcass side 3 hours post mortem by measuring degree of angle between body axis and foreleg (Davis et al., 1978). For that purpose photographic images were taken of carcasses, at distance of approximately $2 \mathrm{~m}$ and a height of $160 \mathrm{~cm}$, parallel to the plane of the carcass and then the angle was calculated in AutoCAD. The size of the angle and intensity of rigor were inversely proportional, e.g. smaller angle meant a higher degree of rigor mortis. For determination of drip loss, colour and marbling, meat samples, $2.5 \mathrm{~cm}$ thick loin chops were taken 24 hours after slaughter from LD, between the 3rd and 4th lumbar vertebrae. Meat samples were weighed and stored for 48 hours at $4^{\circ} \mathrm{C}$ in a container (Honikel, 1998). After storage, meat samples were reweighed and drip loss (\%) was calculated as the difference between sample weight before and after storage divided by the sample weight before 
storage. Sensory and instrumental colour (Commission Internationale de l'Eclairage [CIE] $\left.L^{*} a * b *\right)$ (CIE, 1976) as well as marbling were determined at 24 hours postmortem, after approximatelly 60 minutes of blooming time (Honikel, 1998). $L^{*}, a^{*}$, and $b^{*}$ (CIE, 1976) values were determined using a Minolta Chroma Meter CR-400 (Minolta Co., Ltd., Osaka, Japan) utilizing a 65 light source and a $2^{\circ}$ observer. Colour, marbling and drip loss were analyzed in duplicate. An analytical panel of three trained members assessed sensory colour and marbling of meat samples by using the scaling method (NPPC, 2000).

Hot carcass weight and carcass fat thickness at two points (on the back between the 13th and 15th dorsal vertebrae and at the sacrum where is fat thickness thinnest) were measured. Meatiness (in percentages and kilograms) was determined according to regulation (Anon, 1985) on the basis of hot carcass weight and the sum of carcass fat thickness at two points (on the back and at the sacrum).

\section{Statistical analysis}

Statistical analysis of the results was elaborated using software GrapfPad Prism version 5.00 for Windows, GraphPad Software, San Diego CA, USA, www.graphpad.com. All parameters were described by descriptive statistics (mean, standard deviation, minimum and maximum value). Pearson's correlation was used to determine relationships among different stress, meat and carcass quality parameters. Student t-test was used for testing the effect of blood lactate concentration below and above $12 \mathrm{mmol} / \mathrm{L}$ on $\mathrm{pH}$ value and temperature measured 60 minutes postmortem.

\section{RESULTS AND DISCUSSION}

\section{Characterization of the experimental population}

Characterization of the experimental population is presented in Table 1. In this study, blood lactate ranged from 1.3 to $24.6 \mathrm{mmol} / \mathrm{L}$ which is in accordance with results of other authors, who found values ranging from 1.1 to $20.6 \mathrm{mmol} / \mathrm{L}$ (Edwards et al., 2010a) and from 4.0 to $19.7 \mathrm{mmol} / \mathrm{L}$ (Edwards et al., 2010b). Blood cortisol content varied within studies (Hambrecht et al., 2004; Foury et al., 2005; Hambrecht et al., 2005b), which was also observed in this experiment ( 3 to $248 \mathrm{nmol} / \mathrm{L}$ ). Those variations in cortisol content could be explained by influence of species, breed, time of day, stress, meal, physical and sexual activity and change of environment. Values of $\mathrm{pH}$ after 60 minutes ranged from 5.64 to 6.81 , while after 24 hours were from 5.26 to 5.93. The highest carcass temperature was $40.3^{\circ} \mathrm{C}$ and the highest drip loss of meat samples was $9.50 \%$. There were carcasses without skin blemishes (score 3 ) in the experimental group, as well as those with a maximum score for skin blemishes (score
12). The CIE parameters ranged from 35.11 to 60.22 (CIE $L^{*}$ value), from 4.15 to 11.83 (CIE $a^{*}$ value) and from 2.23 to 7.41 (CIE $b^{*}$ value), while sensory colour from 1.0 to 4.0 .

The average hot carcass weight in this study was 93.46 $\mathrm{kg}$, which was similar to most EU countries (less than 95 $\mathrm{kg}$ ) (Hansson, 2003). Carcass fat thickness ranged from 12 to $36 \mathrm{~mm}$ on the back, and from 5 to $34 \mathrm{~mm}$ at the sacrum. The reason for those variations, especially at the sacrum, was due to the presence of barrows, gilts and boars in the study, since boars have the lowest backfat thickness (Jaturasitha et al., 2006). The average meatiness was $43.79 \%$, which was lower compared to data from $16 \mathrm{EU}$ countries, where average meatiness ranged from 55 to $55.99 \%$ (Hansson, 2003). Unlike in the EU, in this study muscle tissue from the belly was not included in determination of meat yield, so differences in meatiness recorded by these different measuring practices could be up to $10 \%$.

\section{The effect of lairage time}

Relationships among lairage time, blood lactate and cortisol concentration, and meat quality parameters in pigs are shown in Table 2.

Table 1. Characterization of the experimental population $(n=$ 100): Stress, meat and carcass quality parameters

\begin{tabular}{|c|c|c|c|}
\hline Parameter & $\overline{\mathrm{X}} \pm \mathrm{SD}$ & Min & Max \\
\hline Blood lactate (mmol/L) & $10.06 \pm 5.47$ & 1.30 & 24.60 \\
\hline Plasma cortisol (nmol/L) & $58.36 \pm 57.46$ & 3.00 & 248.00 \\
\hline $\mathrm{pH}_{60 \min }^{1}$ & $6.33 \pm 0.21$ & 5.64 & 6.81 \\
\hline $\mathrm{pH}_{24 \mathrm{~h}}^{1}$ & $5.55 \pm 0.13$ & 5.26 & 5.93 \\
\hline $\mathrm{t}_{60 \min }{ }^{2}\left({ }^{\circ} \mathrm{C}\right)$ & $38.58 \pm 0.74$ & 37.10 & 40.30 \\
\hline Skin damages score & $7.09 \pm 2.30$ & 3.00 & 12.00 \\
\hline Rigor mortis $\left(^{\circ}\right)$ & $124.80 \pm 4.62$ & 115.10 & 136.60 \\
\hline Drip loss (\%) & $6.30 \pm 1.40$ & 3.01 & 9.50 \\
\hline$L^{*}$ value $^{3}$ & $50.20 \pm 3.02$ & 35.11 & 60.22 \\
\hline$a^{*}$ value $^{3}$ & $7.71 \pm 1.26$ & 4.15 & 11.83 \\
\hline$b^{*}$ value $^{3}$ & $4.21 \pm 0.96$ & 2.23 & 7.41 \\
\hline Sensory colour ${ }^{4}$ & $2.44 \pm 0.52$ & 1.00 & 4.00 \\
\hline Marbling & $1.30 \pm 0.38$ & 1.00 & 2.50 \\
\hline HCW (kg) & $93.46 \pm 11.25$ & 54.30 & 115.60 \\
\hline FTB (mm) & $21.94 \pm 5.90$ & 12.00 & 36.00 \\
\hline FTS (mm) & $14.51 \pm 5.23$ & 5.00 & 34.00 \\
\hline Meatiness (kg) & $40.99 \pm 4.37$ & 31.80 & 52.20 \\
\hline Meatiness (\%) & $43.79 \pm 1.71$ & 38.18 & 46.61 \\
\hline
\end{tabular}

SD, standard deviation; HCW, hot carcass weight; FTB, fat carcass thickness on the back; FTS, fat carcass thickness at the sacrum.

${ }^{1} \mathrm{pH}_{60 \min }$ and $\mathrm{pH}_{24 \mathrm{~h}}, \mathrm{pH}$ values measured 60 minutes and 24 hours postmortem

${ }^{2} \mathrm{t}_{60 \mathrm{~min}}$, meat temperature measured 60 minutes postmortem;

${ }^{3} L^{*}$, Lightness (a higher $L^{*}$ value indicates a lighter colour); $a^{*}$, Redness (a higher $a^{*}$ value indicates a redder colour); $b^{*}$, Yellowness (a higher $b^{*}$ value indicates a more yellow colour);

${ }^{4}$ Sensory colour scale: 1 = pale pinkish-gray to white; $6=$ dark purplishred. 
Table 2. Correlations among lairage duration, stress and meat quality parameters

\begin{tabular}{|c|c|c|c|c|c|c|c|c|c|c|c|c|c|c|}
\hline Parameters & LT & $\mathrm{Lac}$ & Cor & $\mathrm{pH}_{60 \min }{ }^{1}$ & $\mathrm{pH}_{24 \mathrm{~h}^{1}}{ }^{\prime}$ & $\mathrm{t}_{60 \min ^{2}}{ }^{2}$ & SB & RM & DL & $L^{*^{3}}$ & $a^{*^{3}}$ & $b^{*^{3}}$ & SC & Mar \\
\hline$\overline{\mathrm{LT}}$ & 1.0 & $0.21 *$ & -0.12 & 0.02 & 0.0004 & $\begin{array}{c}-0.14 \\
\end{array}$ & $\mathbf{0 . 3 5} * * *$ & -0.27 ** & $-0.23 *$ & $-0.39 * * *$ & $-0.25^{*}$ & $-0.40^{* * * *}$ & $0.20 *$ & $0.26 * *$ \\
\hline $\mathrm{Lac}$ & & 1.0 & -0.01 & $-0.34 * *$ & 0.03 & $0.37 * * *$ & $0.20^{*}$ & $-0.20 *$ & -0.13 & 0.08 & 0.05 & 0.01 & -0.07 & $0.22 *$ \\
\hline Cor & & & 1.0 & -0.15 & 0.06 & $\mathbf{0 . 2 3}^{*}$ & 0.07 & 0.01 & -0.10 & -0.10 & 0.20 & 0.13 & 0.07 & $0.22^{\dagger}$ \\
\hline $\mathrm{pH}_{60 \text { min }}$ & & & & 1.0 & -0.09 & $-0.16^{\dagger}$ & 0.05 & 0.05 & -0.12 & $-0.19^{\dagger}$ & $-0.23^{*}$ & -0.15 & 0.14 & -0.09 \\
\hline $\mathrm{pH}_{24 \mathrm{~h}}$ & & & & & 1.0 & -0.06 & 0.02 & -0.10 & -0.10 & -0.002 & 0.09 & 0.005 & -0.12 & $0.27 * *$ \\
\hline$t_{60 \min }$ & & & & & & 1.0 & -0.14 & -0.07 & -0.17 & 0.15 & 0.16 & 0.13 & -0.01 & 0.12 \\
\hline SB & & & & & & & 1.0 & 0.002 & 0.05 & $-0.31 * *$ & -0.12 & $-\mathbf{0 . 3 0}$ ** & 0.12 & 0.07 \\
\hline $\mathrm{RM}$ & & & & & & & & 1.0 & $\mathbf{0 . 1 9}^{\dagger}$ & 0.12 & -0.006 & 0.08 & -0.11 & -0.08 \\
\hline DL & & & & & & & & & 1.0 & $0.28 * *$ & 0.02 & 0.12 & $-0.20 *$ & $-0.21 *$ \\
\hline$L^{*}$ & & & & & & & & & & 1.0 & 0.16 & $0.60^{* * *}$ & $-0.60 * * *$ & $-0.29 * *$ \\
\hline$a^{*}$ & & & & & & & & & & & 1.0 & $0.72^{* * * *}$ & $0.20 *$ & 0.16 \\
\hline$b^{*}$ & & & & & & & & & & & & 1.0 & $-0.25^{*}$ & -0.05 \\
\hline $\mathrm{SC}$ & & & & & & & & & & & & & 1.0 & $0.30 * *$ \\
\hline Mar & & & & & & & & & & & & & & 1.0 \\
\hline
\end{tabular}

LT, lairage time; Lac, lactate blood concentration; Cor, cortisol blood concentration; SB, skin blemishes score; RM, rigor mortis; DL, drip loss; SC, sensory colour; Mar, marbling.

${ }^{1} \mathrm{pH}_{60 \mathrm{~min}}$ and $\mathrm{pH}_{24 \mathrm{~h}}$, $\mathrm{pH}$ values measured 60 minutes and 24 hours postmortem.

${ }^{2} \mathrm{t}_{60 \mathrm{~min}}$ - Meat temperature measured 60 minutes postmortem.

${ }^{3} L^{*}$, lightness (a higher $L^{*}$ value indicates a lighter colour); $a^{*}$, redness (a higher $a^{*}$ value indicates a redder colour); $b^{*}$, yellowness (a higher $b^{*}$ value indicates a more yellow colour).

$\dagger \mathrm{p}<0.1 ; * \mathrm{p}<0.05 ; * * \mathrm{p}<0.01 ; * * * \mathrm{p}<0.001$.

With longer lairage time, blood lactate level $(r=0.21$, $\mathrm{p}<0.05)$ and skin blemishes $(\mathrm{r}=0.35, \mathrm{p}<0.001)$ increased, carcasses had a greater degree of rigor mortis $(r=-0.27$, $\mathrm{p}<0.01)$ and meat released less water $(r=-0.23, p<0.05)$. In pigs with longer lairage times, meat became darker, as shown by $L^{*}$ values $(r=-0.39, p<0.001)$ and sensory color $(\mathrm{r}=0.20, \mathrm{p}<0.05)$, as well as less red $(\mathrm{r}=-0.25, \mathrm{p}<0.05)$ and yellow $(r=-0.40, p<0.001)$.

Although lairage time did not have a significant effect on cortisol concentration, other authors found the opposite (Perez et al., 2002; Warriss, 2003a), as cortisol decreased during lairage, particularly at night when pigs rested and became calm. On the other hand, in this study, lairage time was positively correlated with blood lactate, which, as a measure of stress, indicated that a longer lairage caused a higher level of stress. This could be explained by after longer lairage pigs were more susceptible to stress due to longer period of experiencing stressors in lairage (rough handling, fights, change of environment, food deprivation, etc.) (Stam et al., 2000; Bruijnzeel et al., 2001; Stam et al., 2002). Lairage time did not have a significant effect on initial or ultimate $\mathrm{pH}$ values, although higher $\mathrm{pH}$ values were found after longer lairage times in other studies (Perez et al., 2002; Hoffman and Fisher, 2010). This is explained by the fact that reserves of glycogen become depleted during lairage and after a longer lairage there is a lower muscle glycogen content and consequently higher $\mathrm{pH}$ value of meat. As in our study, Hoffman and Fisher (2010) determined lower drip loss after longer lairage. In addition, longer lairage increased the level of skin blemishes on the carcass. The percentage of skin blemishes is higher after a longer lairage time because it increases the aggressiveness of the pigs (Nanni Costa et al., 2002; Perez et al., 2002;
Warriss, 2003a; Guardia et al., 2009). Since the rate of rigor mortis is positively correlated with the content of cortisol and lactate as indicators of stress (Warriss et al., 2003b), a greater degree of rigor mortis after longer lairage indicated a more stressful procedure. Lairage time affected meat colour, so after longer lairage meat became darker, less red and yellow which was also observed by Nanni Costa et al. (2002) and Hoffman and Fisher (2010).

\section{The relationship among stress and meat quality parameters}

Increased levels of blood lactate were correlated with lower $\mathrm{pH}$ values after 60 minutes $(\mathrm{r}=-0.34, \mathrm{p}<0.01)$, and higher temperatures after 60 minutes $(r=0.37, p<0.001)$, more skin blemishes $(r=0.20, p<0.05)$ and greater marbling scores $(r=0.22, p<0.05)$. Rigor mortis was more developed in pigs with higher concentrations of lactate $(r=$ $-0.20, \mathrm{p}<0.05$ ) (Table 2).

As in our study, Edwards et al. (2010a, b) found that the concentration of blood lactate was negatively correlated with the initial $\mathrm{pH}$ value $(\mathrm{r}=-0.25, \mathrm{p}<0.001 ; \mathrm{r}=-0.32$, $\mathrm{p}<0.001)$. Higher drip loss of meat was expected in pigs with increased concentrations of lactate (Edwards et al., 2010a, b), but no significant correlation was determined between these two parameters in this study. Although correlation coefficients between blood lactate and meat quality parameters $\left(\mathrm{pH}_{60 \mathrm{~min}}\right.$ and $\left.\mathrm{t}_{60 \mathrm{~min}}\right)$ were weak, they indicated that exsanguination blood lactate is a potential predictor of postmortem muscle metabolism and meat quality (Edwards et al., 2010b). As in our study, a higher degree of rigor mortis was found in pigs with higher levels of blood lactate (Warriss et al., 2003a). A positive correlation between blood lactate concentration and skin 
damages score indicated that lactate was not only associated with meat quality, but also with the level of stress and procedures prior to slaughter. Rabaste et al. (2007) found that skin blemishes score tended to be higher in pigs after rough preslaughter treatment (pigs moved quickly with an electric prod) compared to gentle (pigs moved slowly with a plastic board or whip), while Edwards et al. (2010c) observed higher concentrations of blood lactate in pigs that experienced more frequent use of electric prods.

Higher levels of blood cortisol were associated with higher meat temperatures $(\mathrm{r}=0.23, \mathrm{p}<0.05)$ and marbling scores $(r=0.22, p<0.1)$. Warriss et al. (2003a) observed increased cortisol concentration in the blood of pigs having more developed rigor mortis.

Initial $\mathrm{pH}$ value was not significantly correlated with most meat quality parameters, except with temperature $(\mathrm{r}=$ $-0.16, \mathrm{p}<0.1), L^{*}(\mathrm{r}=-0.19, \mathrm{p}<0.1)$ and $a^{*}(\mathrm{r}=-0.23$, $\mathrm{p}<0.05)$ parameters of colour. In accordance with our results, Terlow and Rybarczyk (2008) found that a lower $\mathrm{pH}$ value after 40 minutes was associated with a higher temperature. Aaslyng and Barton Gade (2001) found that meat with lower $\mathrm{pH}$ value after 40 minutes had higher drip loss and became lighter. Other authors have found that drip loss increased when $\mathrm{pH}$ values after 45 minutes and 24 hours were lower (Hambrecht et al., 2003; Edwards et al., 2010a, b). Although a positive correlation can be found between initial and ultimate $\mathrm{pH}$ value, it is weak in most studies; $\mathrm{p}=0.14$ (Edwards et al., 2010b), 0.15 (Boler et al., 2008), 0.20 (Aaslyng et al., 2001), 0.33 (Borchers et al., 2007) and 0.44 (Klont et al., 2001). We found that relationship between initial and ultimate $\mathrm{pH}$ was not significant, probably due to the fact that these two parameters were under the influence of different factors. The extent of $\mathrm{pH}$ decline and the finally ultimate $\mathrm{pH}$ are primarily affected by amount of glycogen in muscles at the time of slaughter (Lonergan et al., 2008), while initial pH value depends on rate of postmortem glycolysis which is influenced by genetic (Barbut et al., 2007), pre-slaughter factors (Rosenvold and Andersen, 2003), postmortem carcass chilling (Tomovic et al., 2008) or combinations of all of these (Lonergan et al., 2008).

Several meat quality characteristics are correlated with $\mathrm{pH}$ value after 24 hours. In pigs with lower ultimate $\mathrm{pH}$ values, higher drip loss (Huff-Lonergan et al., 2002; Hambrecht et al., 2003; Edwards et al., 2010b) and lighter colour (Huff-Lonergan et al., 2002; Hambrecht et al., 2003; Boler et al., 2008; Edwards et al., 2010b) were measured. In carcasses with rapid development of rigor mortis, ultimate $\mathrm{pH}$ values were significantly lower (Warriss et al., 2003a). Contrary to those findings, in this study, ultimate $\mathrm{pH}$ value was positively correlated only with marbling, as was also observed by other authors (Przybylski et al., 2007; Boler et al., 2008; Czarniecka-Skubiña et al., 2010). This can be explained by the fact that energy reserves in muscle fibres are distributed among intramuscular fat and glycogen, and muscles with lower glycogen content have a higher intramuscular fat content. Therefore, higher marbling was accompanied by higher ultimate $\mathrm{pH}(\mathrm{r}=0.27, \mathrm{p}<0.01)$, lower drip loss $(\mathrm{r}=-0.21, \mathrm{p}<0.05)$ and darker colour expressed by $L^{*}$ value $(\mathrm{r}=-0.29, \mathrm{p}<0.01)$ and sensory colour $(r=0.30, p<0.01)$, indicating lower glycogen content in muscles. Boler et al. (2010) also found a significant correlation between sensory colour and marbling $(r=0.29$, $\mathrm{p}<0.05)$.

In this study, there was no significant correlation between temperature and other meat quality parameters. Contrary to that, meat temperature after 40 minutes was positively correlated with $L^{*}$ value (Aaslyng et al., 2001) and drip loss (Aaslyng et al., 2001; Hambrecht et al., 2003), while Edwards et al. (2010b) found that increase in temperature reduced the amount of meat exudate. In addition, in the current study, pigs with rapid development of rigor mortis were observed to have a higher meat temperature, increased blood concentrations of cortisol and lactate, and lower ultimate $\mathrm{pH}$ value. Those changes in parameters indicated that stressful procedures prior to slaughter were accompanied by intensive metabolic processes in muscles and, consequently, more rapid development of rigor mortis (Warriss et al., 2003a).

The degree of skin blemishes was negatively correlated with $L^{*}(\mathrm{r}=-0.31, \mathrm{p}<0.01)$ and $b^{*}(\mathrm{r}=-0.30, \mathrm{p}<0.01)$ parameters, because during lairage the number of skin lesions increases (Nanni Costa et al., 2002; Perez et al., 2002; Guàrdia et al., 2009) and meat becomes darker (Jones et al., 1994; Faucitano, 1998; Warriss et al., 1998).

Drip loss was negatively correlated with sensory colour $(\mathrm{r}=-0.20, \mathrm{p}<0.05)$ and positively with $L^{*}$ colour parameter $(r=0.28, p<0.01)$. Other authors have come to the same conclusions (Hambrecht et al., 2003; Edwards et al., 2010b). Additionally, drip loss was lower in meat samples with higher marbling $(\mathrm{r}=-0.21, \mathrm{p}<0.05)$, as also determined by others (Przybylski et al., 2007; Czarniecka-Skubina et al., 2010).

In this study, sensory colour was negatively correlated with $L^{*}(\mathrm{r}=-0.60, \mathrm{p}<0.001)$ and $b^{*}(\mathrm{r}=-0.25, \mathrm{p}<0.05)$ parameters, and positively with $a^{*}(\mathrm{r}=0.20, \mathrm{p}<0.05)$ colour parameter. Higher $L^{*}$ values were correlated with higher $b^{*}$ $(\mathrm{r}=0.60, \mathrm{p}<0.001)$ values, and there was also a high correlation $(\mathrm{r}=0.72, \mathrm{p}<0.001)$ between $a^{*}$ and $b^{*}$ colour parameters, as found previously (Edwards et al., 2010b).

\section{The relationship among blood cortisol concentration and carcass quality parameters}

Table 3 shows correlations between blood cortisol concentration and carcass quality parameters as well as correlations among carcass quality parameters.

Cortisol concentration was positively correlated with hot carcass weight $(r=0.26, p<0.1)$ and with the amount of 
Table 3. Relationship between blood cortisol concentration and carcass quality parameters as well as inter-relationships among carcass quality parameters

\begin{tabular}{lcccccc}
\hline Parameters & Cor & HCW & FTB & FTS & M & Mar \\
\hline Cor & 1.0 & $\mathbf{0 . 2 6}^{\dagger}$ & $\mathbf{0 . 3 3}^{*}$ & $\mathbf{0 . 2 5}^{\dagger}$ & $\mathbf{- 0 . 2 9}^{*}$ & $\mathbf{0 . 2 2}^{\dagger}$ \\
HCW & & 1.0 & $\mathbf{0 . 5 6}^{* * *}$ & $\mathbf{0 . 4 0}^{* * *}$ & -0.14 & $\mathbf{0 . 2 3}^{*}$ \\
FTB & & & 1.0 & $\mathbf{0 . 7 4}^{* * *}$ & $\mathbf{- 0 . 3 9 * * *}$ & $\mathbf{0 . 1 9}^{\dagger}$ \\
FTS & & & & 1.0 & $\mathbf{- 0 . 4 4}^{* * *}$ & 0.15 \\
M & & & & & 1.0 & -0.14 \\
Mar & & & & & & 1.0 \\
\hline
\end{tabular}

Cor, cortisol blood concentration; HCW, hot carcass weight; FTB, fat carcass thickness on the back; FTS, fat carcass thickness at the sacrum; M, meatiness (\%); Mar, marbling.

$\dagger \mathrm{p}<0.1 ;{ }^{*} \mathrm{p}<0.05 ; * * \mathrm{p}<0.01 ; * * * \mathrm{p}<0.001$

fat in the body, expressed as carcass fat thickness on the back $(r=0.33, p<0.05)$ and at the sacrum $(r=0.25, p<0.1)$. Higher cortisol concentrations in the blood correlated with lower meatiness $(\mathrm{r}=-0.29, \mathrm{p}<0.05)$. In accordance with this, Foury et al. (2005; 2007) and Skrlep et al. (2009) have found that high concentrations of cortisol were associated with a greater thickness of subcutaneous fat tissue and lower meatiness. These results indicate that cortisol affects the metabolism of fats and proteins by stimulating the fat deposition at the expense of decreased synthesis and increased protein degradation (Mormede, 2007). In contrast to other authors (Foury et al., 2005; 2007), we found a positive correlation $(r=0.22, p<0.1)$ between blood cortisol concentration and marbling, indicating that cortisol influenced deposition of adipose tissue not only under the skin and around organs, but also between and inside the muscle fibers. It is likely that the same mechanism controls deposition of fat regardless of location in the body, since Huff-Lonergan et al. (2002) have found a positive correlation $(\mathrm{r}=0.38)$ between fat thickness on the back and marbling, which has been also observed in the present study $(\mathrm{r}=0.19, \mathrm{p}<0.1)$

Carcass quality parameters were inter-correlated, where hot carcass weight was associated with fat thickness on the back $(r=0.56, p<0.001)$ and at the sacrum $(r=0.40$, $\mathrm{p}<0.001)$, as well as with marbling $(\mathrm{r}=0.23, \mathrm{p}<0.05)$. Fat thickness on the back and at the sacrum was negatively correlated with meat yield $(\mathrm{r}=-0.39, \mathrm{p}<0.001$, and $\mathrm{r}=$ $-0.44, \mathrm{p}<0.001)$. Similarly to our results, Huff-Lonergan et al. (2002) and Škrlep et al. (2009) found that increasing of hot carcass weight increased subcutaneous fat thickness and slightly reduced carcass meatiness.

\section{The effect of blood lactate concentration on $\mathrm{pH}$ and temperature at 60 minutes postmortem}

Figures 1 and 2 represent $\mathrm{pH}$ values and temperatures measured 60 minutes after slaughter in relation to the blood lactate concentration (below and above $12 \mathrm{mmol} / \mathrm{L}$ ). In the group of pigs with the lower lactate concentration, a

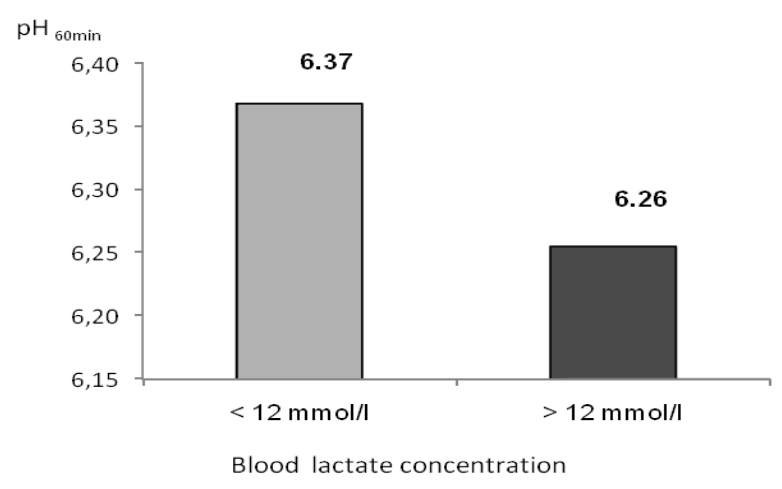

Figure 1. In the group of pigs with the lower lactate concentration, a significantly higher $(\mathrm{p}<0.01)$ average $\mathrm{pH}$ value (6.37) was determined compared to the group of pigs with the higher lactate concentration (6.26).

significantly higher $(\mathrm{p}<0.01)$ average $\mathrm{pH}$ value $(6.37)$ was determined compared to the group of pigs with the higher lactate concentration (6.26). Furthermore, in the group of pigs with blood lactate concentration above $12 \mathrm{mmol} / \mathrm{L}$, meat temperature $\left(38.92^{\circ} \mathrm{C}\right)$ was, on average, higher $(\mathrm{p}<0.001)$ than in the group of pigs with lower blood lactate concentration $\left(38.40^{\circ} \mathrm{C}\right)$. Drip loss did not differ between two groups (data not shown). Edwards et al. (2010b) compared the effect of low (up to $10 \mathrm{mmol} / \mathrm{L}$ ) and high (more than $10 \mathrm{mmol} / \mathrm{L}$ ) lactate concentration on drip loss and found a higher drip loss in the group with a higher lactate concentration. These results support the statement that lactate can be used as a predictor of meat quality (Edwards et al., 2010a) and the concentration of $12 \mathrm{mmol} / \mathrm{L}$ may be taken as a critical value above which the most important meat quality parameters deteriorate.

\section{CONCLUSION}

Lairage time affected stress and meat quality parameters

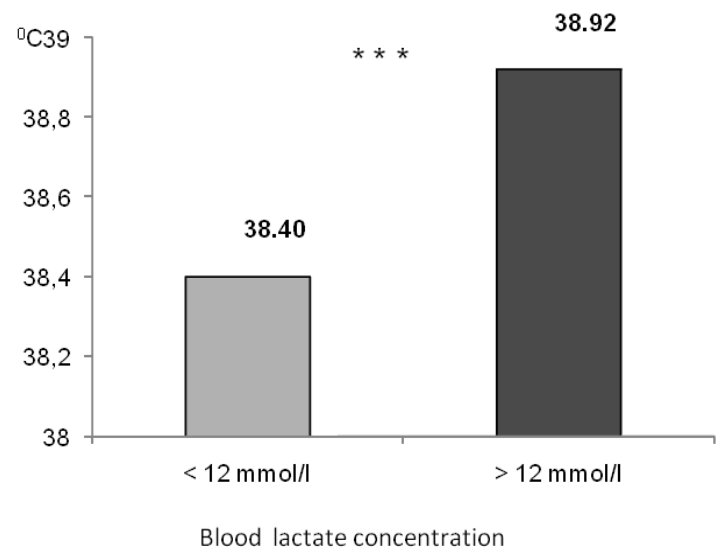

Figure 2. In the group of pigs with blood lactate concentration above $12 \mathrm{mmol} / \mathrm{L}$, meat temperature $\left(38.92^{\circ} \mathrm{C}\right)$ was, on average, higher $(\mathrm{p}<0.001)$ than in the group of pigs with lower blood lactate concentration $\left(38.40^{\circ} \mathrm{C}\right)$. 
and after longer lairage, blood lactate and degree of injuries increased, meat became darker, while drip loss decreased. Higher lactate was associated with lower initial $\mathrm{pH}$ value, higher temperature and skin blemishes score and more developed rigor mortis, suggesting that lactate could be predictor of both meat quality and the level of preslaughter stress. Cortisol affected carcass quality, so higher levels of cortisol were associated with increased hot carcass weight, carcass fat thickness on the back and at the sacrum and marbling, but also with decreased meatiness. The most important meat quality parameters ( $\mathrm{pH}$ and temperature after 60 minutes) deteriorated when blood lactate concentration was above $12 \mathrm{mmol} / \mathrm{L}$.

\section{ACKNOWLEDGMENTS}

This paper was supported by the Ministry of Education and Science, Republic of Serbia, Project "Selected biological hazards to the safety/quality of food of animal origin and the control measures from farm to consumer" (31034). The authors wish to express sincere gratitude to Dr Sheryl Avery and Professor Sava Buncic for their assistance in preparation of the paper.

\section{REFERENCES}

Aaslyng, M. D. and P. Barton-Gade. 2001. Low stress preslaughter handling: effect of lairage time on the meat quality of pork. Meat Sci. 57:87-92.

Anon, 1985. Regulations on quality of slaughtered pigs and pork categorization (Sl. list SFRJ, 2/85, 12/85, 24/86).

Barbut, S., A. A Sosnicki, S. M. Lonergan, T. Knapp, D. C. Ciobanu, L. J Gatcliffe, E. Huff-Lonergan, and E. W. Wilson. 2008. Progress in reducing the pale, soft, and exudative (PSE) problem in pork and poultry meat. Meat Sci. 79:46-63.

Boler, D. D., A. C. Dilger, B. S. Bidner, S. N. Carr, J. M. Eggert, J. W. Day, M. Ellis, F. K. McKeith, and J. Killefer. 2010. Ultimate $\mathrm{pH}$ explains variation in pork quality traits. J. Muscle Foods 21:119-130.

Borchers, N., G. Otto, and E. Kalm. 2007. Genetic relationship of drip loss to further meat quality traits in purebred Pietrains. Arch. Tierz. 1:84-91.

Bruijnzeel, A. W., R. Stam, J. C. Compaan, and V. M. Wiegant. 2001. Stress-induced sensitization of CRH-ir but not P-CREBir responsivity in the rat central nerous system. Brain Res. 908: 187-196.

CIE. 1976. International Commission on Illumination, Colorimetry: Official Recommendation of the International Commission on IlluminationPublication CIE No. (E-1.31), Bureau Central de la CIE, Paris, France.

Czarniecka-Skubina, E., W. Przybylski, D. Jaworska, K. KajakSiemaszko, and I. Wachowicz. 2010. Effect of pH24 and intramuscular fat content on technological and sensory quality pork. Polish J. Food Nutr. Sci. 60:43-49.

Davis, E., W. E. Townsend, and C. H. McCampbell. 1978. Early rigor detection in pork carcasses by foreleg position. J. Anim.
Sci. 46:376-383.

Edwards, L. N., T. Grandin, T. E. Engle, M. J. Ritter, A. A Sosnicki, B. A Carlson, and D. B. Anderson. 2010. The effects of preslaughter pig management from the farm to the processing plant on pork quality. J. Anim. Sci. 86:938-944.

Edwards, L. N., T. E. Engle, J. A. Correa, M. A. Paradis, T. Grandin, and D. B. Anderson. 2010. The relationship between exsanguination blood lactate concentration and carcass quality in slaughter pigs. Meat Sci. 85:435-440.

Edwards, L. N., T. Grandin, T. E. Engle, S. P. Porter, M. J. Ritter, A. A. Sosnicki, and D. B. Anderson. 2010. Use of exsanguination blood lactate to assess the quality of preslaughter pig handling. Meat Sci. 86:384-390.

Faucitano, L. 1998. Preslaughter stressors effects on pork: a review. J. Muscle Foods. 9:293-303.

Foury, A., N. A. Geverink, M. Gil, M. Gispert, M. Hortos, M. Font, I. Furnols, D. Carrion, S. C. Blott, G. S. Plastow, and P. Mormede. 2007. Stress neuroendocrine profiles in five pig breeding lines and the relationship with carcass composition. Animal 1:973-982.

Hambrecht, E., J. J. Eissen, D. J. Newman, C. H. M. Smits, M. W. A. Verstegen, and L. A. den Hartog. 2005. Preslaughter handling effects on pork quality and glycolytic potential in two muscles differing in fiber type compositon. J. Anim. Sci. 83:900-907.

Hansson, I. 2003. Pork production and classification of pig carcasses in European countries. EUPIGCLASS GROWTH Project GRD-1999-10914, Annex 9.

Hoffman, L. C. and P. Fisher. 2010. Comparision of the effects of different transport conditions and lairage times in a Mediterranean climate in South Africa on the meat quality of commercially crossbred Large whitexLandrace pigs. J. S. Afr. Vet. Assoc. 81:225-227.

Honikel, K. O. 1998. Reference methods for the assessment of physical characteristics of meat. Meat Sci. 49:447-457.

Jaturasitha, S., S. Kamopas, T. Suppadit, R. Khiaosaard, and M. Kreuzer. 2006. The effect of gender of finishing pigs slaughtered at 110 kilograms on performance, and carcass and meat quality. ScienceAsia 32:297-305.

Kauffman, G., R. G. Cassens, A. Scherer, and D. L. Meeker. 1992. Variations in pork quality. National Pork Producers Council, Des Moines, IA, USA.

Klont, R. E., B. Hulsegge, A. H. Hoving-Bolink, M. A. Gerritzen, E. Kurt, H. A. Winkelman-Goedhart, I. C. de Jong, and R. W. Kranen. 2001. Relationships between behavioral and meat quality characteristics of pigs raised under barren and enriched housing conditions, J. Anim. Sci.79:2835-2843.

Lee, S., J. M. Norman, S. Gunasekaran, R. L. J. M. Van Laack, B. C. Kim, and R. G. Kaufmann. 2000. Use of electrical conductivityto predict water holding capacity in post-rigorpork. Meat Sci.55:385-389.

Lonergan, S., D. Boler, and S. Moeller. 2008. Pork Quality: pH Decline and Pork Quality. Pork Information Gateway, 1-3.

Warriss, D., S. N. Brown, and T. G. Knowles.2003. Measurements of the degree of development of rigor mortis as an indicator of stress in slaughtered pigs. Vet. Rec. 153:739-742.

Warriss, P. D. 2003. Optimal lairage times and conditions for slaughter pigs: A review. Vet. Rec. 153:170-176. 